\title{
For Kirsty
}

\author{
Remember \\ those Ayrshire summers? \\ Watching salmon leaping \\ in splashes of quick silver \\ under the dark arc of the bridge; \\ eating wild berries \\ snatched from hedgerows \\ with greedy stained fingers; \\ throwing sticks at lazy snakes \\ baking unawares \\ on sun-filled rocks; \\ playing in grey midnight light, \\ our naked feet \\ prickling on shorn hayfields; \\ running through cool fountains \\ of moist \\ shoulder-high ferns; \\ dabbing calamine pink \\ on the red \\ of burning nettle rashes; \\ smelling seaweed and brine \\ in celadon sea \\ breezes; \\ tasting the salt dusting \\ our skin \\ after a day at the shore; \\ never ever brushing \\ the knots \\ from our wild tangled hair. \\ In the long summers of no school \\ the land and her creatures \\ unfolded themselves to us -
}


willing friends -

opening their arms

in companionship,

granting respite

from the pain and sudden violence

of home,

offering solace

for the profuse sadnesses

of childhood. 